\title{
An AdAPTEd EngINeERING DeSign Process: GuIDING TOUCHSTONES
}

\author{
Chelsea Dubiel ${ }^{1}$, Jillian Seniuk Cicek ${ }^{2}$, Roxanne Greene ${ }^{3}$, Shawn Bailey ${ }^{4}$, and Farhoud Delijani ${ }^{2}$ \\ Department of Biosystems Engineering, University of Manitoba ${ }^{1}$, Centre for Engineering Professional Practice \& \\ Engineering Education, University of Manitoba ${ }^{2}$, Shoal Lake No. 40 First Nation ${ }^{3}$, and Faculty of Architecture, University \\ of Manitoba ${ }^{4}$ \\ chelseadubiel@outlook.com
}

\begin{abstract}
The field of engineering needs to develop while healing our relations with the lands, waters, and living systems. Fostering ethical spaces where Indigenous ways of knowing and being and western worldviews can hold space together, and cease to separate the technical from the social, are key to progressing equitably as a society. In the field of engineering within Turtle Island, it is essential that we adapt the engineering design process to reflect this. Following the execution of an Engineering and Architecture transdisciplinary Design Build course at University of Manitoba, and in partnership with the Shoal Lake No. 40 First Nation, it was acknowledged by stakeholders that further analysis of this project could establish lessons learned. This paper speaks to engineering education practice. The objective of this research is to develop recommendations for how the engineering design process can make space for Indigenous ways of knowing and being. Shoal Lake No. 40 community members, one engineering contractor, and four university faculty members were asked their perspectives on the development and implementation of two projects conducted with the community members and on the First Nation lands. Through the co-analysis of these open-ended discussions, recommendations were developed for how the engineering design process can integrate four touchstones external to the design process. The touchstones enable an engineer to perceive the design process and establish core intentions for a project that creates space for Indigenous values and principles and western worldviews.
\end{abstract}

Keywords: engineering design process, Indigenous knowledges, guiding touchstones, relationships, engineering education practice

\section{INTRODUCTION}

In Winnipeg, Manitoba, we are living on Treaty 1 lands. In Manitoba there is an Indigenous population of $17 \%$ [8], and Indigenous peoples are the fastest growing demographic in Canada. It is evident that "the explicit and intentional incorporation of Indigenous values, knowledges, perspectives, and design principles in engineering education programs and research in Canada is still nascent" [16]. There is an ongoing history of wrongdoings being done to Indigenous Peoples and communities by engineering and government groups within the province of Manitoba. A major project in Manitoba where the impact on the Indigenous peoples and the environment were dismissed and not considered was the Winnipeg Aqueduct, constructed in 1919, which provides the City of Winnipeg with clean drinking water. This project resulted in the isolation of the community members of Shoal Lake No. 40 First Nation (SL40) for 100 years [3]. Progressive development and pollution by cottage-goers tainted SL40's water, that ultimately led to a boil water advisory to be in place since 1997 [3]. Insufficient water treatment plant (WTP) infrastructure and the high cost of construction, due to the forced isolation, resulted in the absence of basic human rights within the community. In July 2019, the construction of Freedom Road, a highway connecting SL40 and the Trans-Canada Highway Number 1, was completed and land access to SL40 has been restored for the first time in 100 years. The community is now in the process of constructing a WTP and a new school. SL40 is just one example of the enduring effects colonization has and the negative impact that traditional engineering practices have on a community. It is essential that we continue adapting the engineering practices to reflect society, which means acknowledging and respecting Indigenous values and principles, and the importance of community engagement.

The objective of this research is to develop recommendations for how the engineering design process can make space for Indigenous ways of knowing and being. This will be done by exploring the perspectives of SL40 community members and university faculty who developed and implemented the SL40 "Design Build" and the contractor for Freedom Road, Sigfusson Northern. As well, the perspectives of two faculty members with expertise in engineering projects in Indigenous communities were also incorporated within the findings.

\subsection{Background}

1.1.1.The Design Build Course. In partnership with SL40 community members, Shawn Bailey, Farhoud Delijani, and Jillian Seniuk Cicek developed a trans-disciplinary approach to engineering education though the delivery of a "Design Build" course offered by the Faculties of Engineering and Architecture at University of Manitoba (UofM) [15]. The course involved the design and construction of a picnic shelter off Freedom Road. In May-June 2019 the course was led by two instructors from the Faculties of Engineering and 
Architecture. They provided technical guidance and support to the 20 student participants (10 from each faculty). Further guidance and support was provided from an educational researcher and cultural advisor and a teaching assistant from the Faculty of Architecture. The course involved all-day studios, twice a week for a six-week period where students had the opportunity to visit the community and proposed site, participate in ceremony and a powwow, and speak with Elder Norman Meade at the UofM. In-person consultations with the community members took place as well as drawings and prototypes were shared to communicate concepts that were collaboratively developed. Following the approval of a concept from the community, a week (5 working days) of prefabrication took place at the UofM Alternative Village. The course was temporarily paused the following week to permit community members to clear the site and pour the concrete slab foundation. The proceeding week took place at the SL40 site, where the students and instructors lived within a work camp ran by and in the community. Community members who were a part of a youth carpentry program along with the students and instructors constructed the picnic shelter over this 5-day period.

1.1.2. The Engineering Design Process. In general, the traditional iterative engineering design process includes five main components: define, ideate, prototype, build, analyze. These stages are arguably missing building relationships and understanding, essential for creating a successful project with any stakeholder. Historically, engineers have been trained and practiced in separating the technical aspects of a project from the social [15][14][12][4][18]. This dualistic ideology does not align with the goal of social, economic, and environmental sustainability or acknowledge the interconnectedness between them. Building relationships with stakeholders and connecting the social and the technical, is key for making space for Indigenous perspectives. The current social climate has ignited questions of how the engineering design process can continue to advance. For example, Stanford University has added two additional steps prior to problem definition: accept and empathize [9][5], and there is evidence of a growing focus on social-ecological equity and sustainability, especially within civil and structural engineering literature [7].

\subsubsection{Indigenous Knowledge and Engineering Design. It} is important to understand what Indigenous knowledge is and how it relates to engineering design.

Various aspects of approaching the integration of Indigenous Knowledge (IK) and Traditional Ecological Knowledge (TEK) within engineering design have been studied [8][17][7]. Friesen and Herrmann discuss the integration of Indigenous Knowledge and perspectives in engineering curricula, identifying a three-step process: (i) listening and understanding; (ii) knowledge; and (iii) experience. They argue that as engineers we must deconstruct before reconstructing the way we think, setting aside what we think we know as engineers and being open to re-learning in order to comprehend the value of IK in the engineering design process [8]. They outline Indigenous design principles that should have space in engineering curricula, including commitment to relationships, culturally relevant design, respecting Mother Earth, fostering a sense of community, and embracing the Seven Generations view.

Voyde and Morgan outline how Mātauranga Māori, Indigenous knowledge of the Māori people of Aotearoa, relates to their relationship with ecosystems and shares values with sustainable design paradigms [17]. The people of Aotearoa New Zealand maintain a perspective that "tangata whenua" (people of the land) see themselves as not only "of the land" but "as the land" and Kaitiakitanga is the ethic of guardianship over the land [17]. This holds individuals to a level of accountability and reciprocity which is desired in ecological engineering. It is possible to see commonalities between the application of Māori landowner values and "new" design paradigms such as low Impact Design, Low Impact Urban Design and Development, and Water sensitive Urban Design. Māori are willing to share their traditional knowledge but on the basis that they can retain control of the information and the way it is used [17]. It is often difficult for scientists within a Western paradigm to access the knowledge but is one of the most important contributions that Māori can bring to sustainable design [19].

Annishinaabe knowledge is also fundamental for sustainable design as there are "strong epistemological relationships and common principles shared by the field of ecological engineering, resilience research, and Anishinaabe culture" [7]. In analyzing Anishinaabe cosmology and ecological engineering, Droz discerned that resilient ecological engineered design is founded on learning relationships, values, and stories focusing on the land-based way of learning [7]. Droz outlined seven design phases incorporating these values:

1. Identify the design team;

2. Create the foundation;

3. Engage social-ecological and traditional learning;

4. Vision the whole and inventory creation;

5. Identify design goals, create, and evaluate options;

6. Design creation and implementation; and

7. Evaluate and learn for adaptation.

IK is "the culturally and spiritually based way in which Indigenous people relate to their ecosystems, a lived relationship rather than a "body of knowledge." [7]. The author establishes that IK is a living thing, not an inanimate object to be utilized as a disposable resource. These values align with ecological and environmental engineering design [7][17]. 


\section{METHODS}

SL40 First Nation is an Ojibwa or Ontario Saulteaux First Nation located in the Eastman Region of Manitoba and the Kenora District of Ontario [1]. It is a member of the Grand Council of Treaty 3. As the first author was a student participant in the Design Build course and conducted this work as part of a graduation thesis project in the Department of Biosystems Engineering, it is important to situate her within this work. The First author is a second-generation settler immigrant, born on Treaty 1 lands, neighbouring Treaty 3. She has a Canadian born father with Polish and Ukrainian ancestry and a mother born and raised in South America. Growing up, she was highly influenced by her Chilean family's political involvement and fight for human rights, deeply engraining a drive for social justice. She spent summers on the land with a close Oji-Cree family, and through these relationships, a deep commitment to family, community, and the land-based way of life grew within her. She acknowledges the value in reciprocity and the obligation to utilize privilege through reconciliation in the field of engineering.

The experiences and perspectives shared by stakeholders of the Design Build course and community project were viewed through Etuaptmumk, TwoEyed Seeing, as the conceptual framework [10]. Two-Eyed Seeing is the guiding principle of learning to see from both Indigenous and Western perspectives and that together they benefit all. Having the work embody this guiding principle actively demonstrates the strength of creating space for both Indigenous and Western perspectives and ultimately, transdisciplinary work.

\subsection{Methodology}

A participatory action research (PAR) methodological approach was taken [13] with SL40 community members to explore the planning, implementation, and outcomes of two recent engineering projects in the SL40 community: (1) the construction of a community picnic shelter through the SL40 Design Build course, offered by the Faculties of Engineering and Architecture at the UofM in Summer 2019; and (2) the construction of Freedom Road, a project sponsored by the Federal, Manitoba, and Ontario Governments, which opened in June 2019. PAR, a qualitative research methodology anchored in action research and social justice [2], enables the participants to lead the research, facilitating the description and development of an understanding of stakeholder perspectives [13]. Historically, mainstream evaluation methods have disrespected Indigenous participants and communities, and guiding principles for evaluators have been developed in a Western context which does not acknowledge Indigenous peoples as active members in these systems [11]. Approaching research from
Indigenous perspectives includes: (i) setting the purpose and goals by community agenda; (ii) utilizing more than just a quantitative methodologies; (iii) collecting data that reflects spiritual, cultural, historical, social, and emotional information; (iv) presenting data graphically or within narratives; and (v) sharing of findings with community members [11]. Receiving approval from the community for this research was the primary step in moving forward with the work. The first author sought counsel from the SL40 Community counsellor (the third author) for how to engage with stakeholders and which questions to ask. In addition to PAR, methods of Indigenous evaluation and boundary crossing were applied for an integrated evaluation method [11][2]. Boundary crossing happens when professionals need to "enter onto territory in which we are unfamiliar and, to some significant extent therefore unqualified" [2]. Four learning mechanisms for boundary crossing have been established: identification, coordination, reflections and transformation [2]. Identification and reflection are two dialogical mechanisms that can be used to establish and construct boundaries throughout the research, i.e. situating oneself in the work based on one's lived experiences and the current social-political climate. Coordination and transformation are useful during the analyses of the research and can be used to effectively communicate efforts between worlds, i.e. engineering and Western perspectives with IK, and adapt the engineering design process to make space for IK.

The unique stakeholder perspectives and the respective relationships between stakeholders were examined through conversational, open-ended interviews. Guiding questions for open-ended interviews were developed based on personal insights and were categorized within four realms: Process, Relationships, Means, and Sustainability. As the first author was an active participant within the Design Build course the guiding questions were based on lived experiences. Indigenous evaluation methods, boundary crossing theories, and ideas of ethical space reviewed also influenced the guiding questions [11][2][6]. The guiding questions were grouped into similar themes or topics, and from this the four realms were formed. Process represents the development of the entire project from beginning to end; Relationships represents the connections between different parties; the Means refers to a project's physical and technical aspects; and Sustainability looks with a Seven Generations view and the maintenance and interconnectivity of the social, economic, and environmental elements.

Participatory discussions took place with six community members in the community band office and one Elder in their home on March 12, 2020. Following this, over the phone discussions took place with one engineering contractor and two UofM faculty stakeholders ${ }^{1}$. In addition, over the phone discussions took place with the Randy Herrmann, Director

${ }^{1}$ Due to Covid-19 it was not possible to meet with participants in person or to co-analyze the findings 
of ENGAP (Indigenous Access program) in the Price Faculty of Engineering, and Peter Kulchyski, Professor in the Department of Native Studies, both at the UofM. These latter two individuals were not directly involved with the projects but offered valuable perspectives due to their personal and professional knowledge of engineering projects with the local Indigenous communities. The first author summarized all transcripts graphically to align with the four realms. The interpretation of the findings were discussed over the phone with the third author, the SL40 community councilor ${ }^{1}$.

\section{FINDINGS}

The findings are based on open-ended discussions and shared meanings with SL40 members, Tom Campbell (a community Elder), the Design Build professors, the contractor of Freedom Road, and our lived experiences of the SL40 Design Build and Freedom Road projects. The findings are represented within the four realms: Process, Relationship, Means, and Sustainability. They are presented here as Stories Shared and Actions. Actions reflect suggestions made by stakeholders from experiences of the Design Build and Freedom Road projects through the stories shared.

\subsection{Process}

3.1.1. Stories Shared. The use of cedar as the main construction material for the picnic shelter in the Design Build was acknowledged by the community members and professors as an important aspect that greatly impacted the feeling on site. A sacred fire was lit at the beginning of construction and throughout the construction the fire was fed by cedar sawdust from planed boards, creating a woody aroma for the duration of construction. The Elder shared various stories acknowledging the importance of the inclusion of TEK in projects and what they refer to as "interactive science with tradition." The Elder told a story (paraphrased here): There was an archeologist who was doing a dig for a loss of use study for wild rice, and she went to the site where they thought graves would be, but she was unable to find anything. She went to the Elders and they asked for tobacco and two or three gifts. The Elders went and had a pipe ceremony, they took the tobacco, smoked it, and one of the Elders has a dream, a vision, that night and told his friends about it. They paddled there and tied ribbons on some trees. The archeologist came the next day wondering what to do. The Elders instructed that those trees were marking grave sites. They dug and there they were... It was communicated that understanding the project and process takes time; to not be afraid to move away from what is conventional to the way things were done in the past, as these ways can lead to a project being conducted in a good way. The contractor for Freedom Road recognized the importance of unconventional ways:... when you start meeting some of the community members and start realizing the significance of what you are actually building to someone who lives there, to somebody who has gone through the hardships... The community engagement meetings provided the contractor with the opportunity to be with, and in the community, allowing them to view the project as something more substantial than initially perceived.

3.1.2. Actions. Community members and the Elder recommended asking the community what initial steps should be taken before the project begins, and ensuring Elder guidance right from the start of the project to establish good intentions. The Elder also recommended that an orientation for personnel involved in the project from outside the community could be conducted, as well an evaluation postproject to provide a means of reflection and lessons learned for all stakeholders for how things can be continued or rectified in the next project.

\subsection{Relationships}

3.2.1. Stories Shared. During the summer of 2019 a student participant with the Design Build asked an Elder from the Indigenous Student Centre in Migizii Agamik on UofM Fort Gary Campus how they could feel comfortable on the job site. The Elder advised, it's not about you feeling comfortable, but it's about when the community members are ready to make you feel comfortable in the community. As non-Indigenous engineers it is important to place ourselves as guests on this land. During the Design Build course, a football/soccer camp was organized by the first author and a community member. The community members who participated in the dialogues for this research acknowledged that this event showed an investment by students and faculty in more than just the project itself - it was an investment to build relationships. It was also recognized that within the Design Build course, friendships were made through the process of making something together. The community members and the Elder shared many stories of projects that have gone astray due to the lack of engagement with community members, and lack of transparency. This demonstrates that engineering is not apolitical and that much care is needed to grow and establish relationships - the social aspects inherent in all projects. The contractor of Freedom Road acknowledged that there was trust issues at the beginning of the Freedom Road project, but with time and the delivery of promises that were made, trust grew between the two parties. Relationships and trust take time and intention to build.

3.2.2. Actions. It was recommended that connecting with the people who are affected by the project creates a respectful relationship from the start. The Elder and their family described this as a two-way protocol: ...so we need to learn what is going on out there and how they are doing and how making it sustainable and environmentally friendly and all those things, and then they need to know how we are doing it here and want to do it... you are integrating the business model of delivering a project, with the community 
way of life... It was also acknowledged that within any relationship one must be ok with knowing that mistakes happen, and one must be prepared to apologize and rectify the situation when an error does occur. Furthermore, the transdisciplinary approach was recognized as extremely valuable in the Design Build, having community members and engineering and architecture students interact provided a new appreciation for what everyone had to offer.

\subsection{Means}

3.3.1. Stories Shared. When working with the land the Elder brought up the idea of territory and what defines it. The Elder stated that their territory was marked by how far you could paddle in a birch bark canoe in any direction, within one day. That is about $25 \mathrm{~km}$, and if you go $25 \mathrm{~km}$ in any direction from the Elder's house you get to the Shoal Lake watershed.

Peter Kulchyski discussed the utilization of valued ecological components to rate what is valuable on the land. The material paradigm of it suggests that one piece of land is equivalent to any other piece of land. It was suggested that there are two main problems with the way this functions that lead to the belief that 1) material design solves problems, and 2) modernism is the best lifestyle. To offset these assumptions, it is recommended to ask oneself three essential questions during the design process: "What does the structure say?", "What is the good life?", and "Is this project actually needed?".

Shawn Bailey, one of the instructors of the Design Build and an author here, shared a story of northern community that had only blue buildings. When the community was asked why they had so many blue buildings, they said they didn't know why; they don't even like blue. This story is an example of how the consultant who built the structures did not speak or work with the community, ultimately displaying a lack of investment in the community and producing what seemed to be "off the shelf" designs. Conversely, Peter Kulchyski shared a story about how homes in Coville Lake, Northwest Territories are built in a semi-circle around the lake, a central part of the community. The physical shape of the houses reflects the community's relationship with the lake and their community centered family dynamics, a reflection of community values. As Peter Kulchyski explains, "the physical structure says community". These examples demonstrate how the physical use and function can and should reflect community values, and these values should be communicated to the project team.

It was iterated by the professors of the Design Build course and community members involved that the Design Build was a knowledge-sharing experience. The engineering students were able to see how architecture students bring into the design the consideration of experience, beauty, as well as situating the design into the landscape itself. In addition, having a transdisciplinary and cross-cultural approach within the Design Build promoted technical sharing and learning to occur naturally between the engineers, architects, and community members. The Design Build grew the platform for young members of the community to be trained in carpentry and roofing, as community members used their skills to build picnic benches for the site, and then moved on to fixing community members' roofs. It was suggested that the creativity of the project came from the interconnections between the groups of team members and the site. It was indicated the transdisciplinary approach to the Design Build was an innovative way of designing the physical structure. It was discussed that the structure itself does not necessarily have to be beautiful, but it must be understood. Once the structure is understood, its importance can be acknowledged.

Developing a joint venture was one of the findings that also came out of the Freedom Road project, proving shared labour and shared equipment between the contractors and community members mutually beneficial, and enabling a platform to support future projects. In addition, having a variety of levels of government involved with Freedom Road was suggested by the contractor as one of the ways the project was innovative. Having a project be innovative is important as it allows for optimal use and function of the design, with respect to the time and social climate it is designed within.

3.3.2. Actions. The importance of ownership came up a couple times during the open-ended discussions and it was noted that, "When people feel like they are involved [in a project] then they are going to look after it more." This can be seen within the Design Build as well as from the joint venture established by the Freedom Road project, as community members were the core of the building team. The importance of immersing oneself into community in a respectful way was established as key in building a good relationship of understanding with the community, which translates into understanding of the means (or physical work/object). For personnel external to the community, an allotted time based on the scale and scope of the project that individuals must spend on the land and with community members to gain a deeper appreciation and understanding for the work was recommended as essential in developing a project in a good way.

The need for bringing understanding and beauty to engineering was noted, such as having community tours of the building site, partaking in ceremonies, or creating murals that honour what has been created. The incorporation of community engagement and ceremony throughout the project development permitted external personnel, such as engineers, to see the land impacted by the site in a new way.

\subsection{Sustainability}

3.4.1. Stories Shared. The Design Build was acknowledged to be one project of many. There were two projects that were 
developed prior to the Design Build in partnership with the Faculty of Architecture at UofM: a community conceptual design, and a conceptual design of the powwow grounds. Based on the conceptual powwow ground designs, funding has been received for the formal powwow ground design and a request for proposals has been released for tender in early 2020. In addition, there are two offshoot projects as a result of the Design Build. There is a community garden planned for the Design Build course in the future (unfortunately, cancelled in 2020 and 2021 due to the COVID-19 pandemic, but planned for 2022), and the Sea Can, which was used for material storage and transport during the Design Build, has been donated to the community and will be developed potentially into a youth-run store. The professors of the Design Build shared the rewarding experience of bringing students out onto the land, providing a space for the landbased experience, and inspiring students for their future studies and careers. This experience gave the professors time to reflect on their own careers and what they consider meaningful work.

3.4.2. Actions. One of the long-term impacts of the Design Build was seen in the development of job skills for local workers. As mentioned, the community members who were part of the Design Build used their skills to construct picnic benches and fix community members' roofs. Additionally, the importance of incorporating Indigenous perspectives into engineering curricula was acknowledged. Questions were asked about how we can use technology to increase collaboration through the design charettes in future Design Build initiatives. The importance of taking students into ceremony as a key to learning and source of inspiration, and having land-based experiences were also noted. Having joint-venture capacity building initiatives like Freedom Road was seen as way of creating sustainable partnerships moving forward, similar to the continuation of the Design Build course.

\section{DISCUSSION}

The Guiding Touchstones: Reviewing the findings with the SL40 Community councilor confirmed the four realms and highlighted that the contractor's perspectives on the importance of Freedom Road changed over time in the community and from community engagement meetings. The first author also experienced this as a student in the Design Build. When the sacred fire was lit on the site, the smell of burning cedar created a grounded feeling to the job. It created a moment of gratitude and realization that this was more than just a picnic shelter: it was a celebration and acknowledgement of the Process, Sustainability, Means, and Relationships. The engineering design process neglects to bring an engineer back to the core intentions, to support grounding oneself.

Recommendations of how the engineering process can adapt to make space for Indigenous ways of knowing and being can exist within four touchstones. These Touchstones, based on the authors own experiences and interpretations of the findings, supported by the community councilor and the first author's graduation thesis advisors, are placed in a circular form around the design process as seen in Fig. 1.

Figure 1 reflects that the touchstones are interwoven and omnipresent and can be referred to at any point during the design process. It is important to acknowledge both the unconscious and conscious way the medicine wheel

Dedication and trust in the time to form a continuity of physical, emotional, mental, and spiritual experience in the space between tangible efforts (Process)

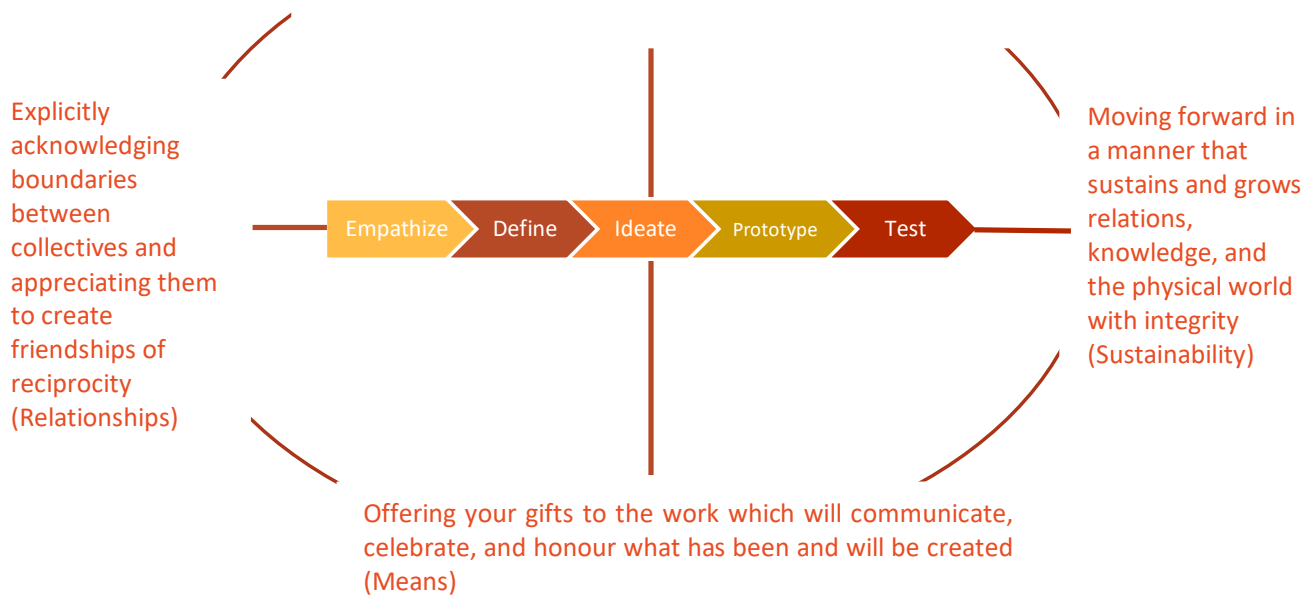

Fig. 1. Pictorial depiction of the Guiding Touchstones. 
teachings influenced the guiding questions and framed the findings. As a non-Indigenous person, it is important to remember that Indigenous knowledge is not a commodity to be utilized or appropriated. The Design Build's approach to collaborative design naturally permitted participants to experience the design process with an outlook of Etuaptmumk, Two-Eyed Seeing.

The pictorial depiction utilizes empathy in the central design process as suggested by Stanford University [9]. A variety of design processes have been developed and depending on the work being conducted, the design process can change or adapt as necessary [9][5][7]. The touchstones act as checkpoints through the design process, a way to pause during any stage of a project and reflect on the current relationships, social climate, means, and progress.

The touchstones - a space external to the design process itself - permit a way to become more mindful, reminding oneself of the intentions and project goals (as they evolve and change). The touchstone on the top of Fig. 1 reminds us to have trust in the Process. Although events through the process may not seem connected to project, it is in those moments when projects develop in a good way. The right touchstone speaks to Sustainability - a commitment to the Seven Generations way of thinking [8]. The touchstone depicted at the bottom refers to the Means and offering one's creativity to the technical development of the project. The left touchstone speaks to Relationships and provides an opportunity to think about boundary crossing, to become self-aware, and situate oneself as a visitor first. Then one can acknowledge and respect others. The figure is depicted in various shades of red, as guided in consultation with the community councilor.

\section{CONCLUSION}

Exploring SL40 First Nation community members', the contractor for Freedom Road, and UofM faculty perspectives' of the implementation of the projects, SL40 "Design Build" and Freedom Road through open-ended discussions, recommendations have been made for how the engineering design process can make space for Indigenous ways of knowing and being. Shared qualitative data and recommendations were developed in partnership with a SL40 Community councilor to integrate touchstones external to the design process. The touchstones enable an engineer to perceive the design process and Indigenous epistemologies with the purpose of establishing core intentions and goals for the project that make space for Indigenous values and principles.

The strength of this work is rooted in the recommendations developed using a community-centered design approach with the community. The perspectives are grounded in the community members, the contractor, and UofM Faculty experiences of the Design Build and Freedom
Road projects, as well as professional knowledge of engineering projects completed with Indigenous communities. The limitations of this study were due to time constraints as dictated by the thesis course structure, which impacted the researcher's ability to conduct more than one open-ended community discussion and develop long-term relationships with the community Elder and the contractor. All which potentially limited the conversational depth. In addition, due to the Covid-19 pandemic, many of the discussions were delayed and had to be held over the phone, when the preference would have been face-to-face discussions. This situation also limited the ability to discuss the findings with SL40 community members, ultimately impacting the amount of feedback the community could have provided on the findings. Ideally with this work, the findings would have been brought back to the community in order to analyze in depth together.

The work is centered on projects completed with SL40 and reflects only the interactions and understandings with SL40. Shawn Bailey, Farhoud Delijani, and Jillian Seniuk Cicek will continue to grow in partnership with SL40 through continued offerings of future Design Build courses. Sigfusson Northern has been awarded the contract to construct SL40's WTP, thus continuing this relationship. Overall, we must engage in more complex discussions regarding our capitalist system and economic ideologies where everything is at the whim of funding and timelines, and question how these ultimately fit - or don't fit - within a sustainable world that respects Indigenous knowledges.

\section{Acknowledgements}

The first author thanks Roxanne Green, Aaron Balan, and all the community members for their willingness to share knowledge with her. She also thanks the community Elder Tom Campbell, and Randy Herrmann, for their guidance during the early stages of discussions. Thank you to Peter Kulchyski and Sigfusson Northern for taking the time to speak and provide insights with the first author. The first author is grateful for her advisors Jillian Seniuk Cicek, Shawn Bailey, and Farhoud Delijani for all their guidance; they have truly brought diverse teachings, and contribute to quality education and a love for engineering. This research was approved by the UofM Ethics Board, and by Roxanne Green on behalf of SL40 First Nation.

\section{References}

[1] About Shoal Lake \#40. Shoal Lake \#40. C2019, [Online], Available from https://www.sl40.ca/about.htm. (accessed: 03/13/2020).

[2] Sanne F. Akkerman and Arthur Bakker, "Boundary Crossing and Boundary Objects", Review of Educational Research, $81(2)$ $132-$ 169, https://doi.org/10.3102/0034654311404435, 2011.

[3] Darren Bernhardt, "A century of water: As Winnipeg aqueduct turns 100, Shoal Lake Finds Freedom," CBC 
Manitoba. Available as of June 2, 2019, from https://www.cbc.ca/news/canada/manitoba/winnipegaqueduct-shoal-lake-100-years-1.5152678

[4] Linda Clarkson, Vern Morrissette, and Gabriel Regallet, Our responsibility to the Seventh Generation: Indigenous Peoples and Sustainable Development Winnipeg, MB: International Institute for Sustainable Development. 1992, 44 pp. Available as of January 20, 2020, from https://www.iisd.org/pdf/seventh_gen.pdf

[5] Design Your Life. Stanford Life Design Lab. c2018, [Online], Available from http://lifedesignlab.stanford.edu/. (accessed: 0/11/2020)

[6] Chloe Dragon Smith, "Creating Ethical Spaces: Opportunities to Connect with the Land for Life and Learning in the NWT," The Gordon Foundation, Jane Glassco Northern Fellowship, pp. 11, Toronto, ON. Available as of April 8, 2020, from https://gordonfoundation.ca/resource/chloe-dragon-smithpolicy-paper/.

[7] Pennelys Droz, "Biocultural Engineering Design for Indigenous Community Resilience," University of Arizona, Tuscon, AZ. 2014, Available as of April 17, 2014, from https://repository.arizona.edu/handle/10150/323449

[8] Marcia Friesen, and Randy Herrmann, "Indigenous Knowledge, Perspectives, And Design Principles in the Engineering Curriculum," in Proc. CEEA-ACEG Canadian Engineering Education Conference (CEEC18), pp. 5, Vancouver, BC. June 3-6, 2018.

[9] Rikke Friis Dam, and Teo Yu Siango, "5 stages in the design thinking process," Interactive Design Foundation. n.d., [Online], Available from https://www.interactiondesign.org/literature/article/5-stages-in-the-designthinking-process. (accessed: 2020/03/10).

[10] Institute for Integrative Science and Health, "Guiding Principles (Two Eyed Seeing) | Integrative Science", n.d., [Online], Available from http://www.integrativescience.ca/Principles/TwoEyedSeei ng/ (accessed: 8/12/2020).

[11] Alice J. Kawakami, Kanani Aton, Fiona Cram, Morris K. Lai, and Laurie Porima, "Improving the practice of evaluation through indigenous values and methods", Hülili: Multidisciplinary Research on Hawaiian Well-Being, vol. 4, no.1, pp. 219-242, 2007.
[12] Peter Kulchyski, "Manitoba Hydro: How to Build a Legacy of Hatred", Canadian Dimension, Vol 38, no. 3, Available: https://canadiandimension.com/articles/view/manitobahydro-how-tobuild-a-legacy-of-hatred-peterkulchyski (Accessed: 2020/02/10).

[13] Cathy Macdonald, "Understanding Participatory Action Research: A Qualitative Research Methodology Option", Canadian Journal Of Action Research, vol. 13, no 2, pp. 34-50, https://doi.org/10.33524/cjar.v13i2.37, 2012.

[14] Joel Alejandro Mejia, and Matias N. de Paula, "Ingeniero como vos: An analysis of the Mby'aGuaran'1 Practices Associated with Engineering Design", Proceedings of the 126th ASEE Annual Conference \& Exposition, pp. 12, Tampa, FL. June 16-19, 2019.

[15] Jillian Seniuk Cicek, Marcia Friesen, and Shawn Bailey, "Development and Assessment of an EngineeringArchitecture Transdisciplinary Design and Build Studio Course in Partnership with the Shoal Lake First Nation Indigenous Community", Proceedings of the 48th Annual Frontiers in Education (FIE) Conference, pp. 6, Cincinnati, OH. October 16-19, 2019.

[16] Jillian Seniuk Cicek, Afua Mante, Carolyn Geddert, and Leah Fontaine, "Engineering Education Re-interpreted Using the Indigenous Sacred Hoop Framework," in Proceedings of the 8th Research in Engineering Education Symposium: Translating Research into Practice (REES), pp. 9, Cape Town, South Africa. July 10-12, 2019.

[17] Emily Voyde, and Te Kipa Kepa Brian Morgan, "Identifying commonalities between Indigenous values and current sustainable design concepts in Aotearoa New Zealand," AlterNative: An International Journal of Indigenous Peoples, vol. 8, no. 2, pp. 215-229, https://doi.org/10.1177/117718011200800209, 2012.

[18] James B. Waldram, "Manitoba History: Native People and Hydroelectric Development in Northern Manitoba, 19571987: The Promise and the Reality," Manitoba History, vol. Spring 1988, no. 15, 1988. Available as of October 23, 2012 from http://www.mhs.mb.ca/docs/mb_history/15/hydroele ctricdevelopment.shtml

[19] Priscilla Wehi, "Indigenous ancestral sayings contribute to modern conservation partnerships: examples using Phormium tenax," Ecological Applications, vol. 19, no. 1, pp. 267-275. https://doi.org/10.1890/07-1693.1, 2009. 